\title{
Commentary: Finding a cancer in the haystack?
}

\author{
Sudish C. Murthy, MD, PhD, FACS, FCCP
}

\footnotetext{
From the Department of Thoracic and Cardiovascular Surgery, Heart and Vascular Institute, Cleveland Clinic, Cleveland, Ohio.

Funded by the Cleveland Clinic and in part by the Daniel and Karen Lee Endowed Chair in Thoracic Surgery held by Dr Murthy.

Disclosures: Author has nothing to disclose with regard to commercial support.

Received for publication July 24, 2019; accepted for publication July 25, 2019; available ahead of print Sept 11, 2019.

Address for reprints: Sudish C. Murthy, MD, PhD, FACS, FCCP, Department of Thoracic and Cardiovascular

Surgery, Cleveland Clinic, 9500 Euclid Ave, Desk J4-1, Cleveland, OH 44195 (E-mail: murthys1@ ccf.org).

J Thorac Cardiovasc Surg 2020;159:327-8

$0022-5223 / \$ 36.00$

Copyright (C) 2019 Published by Elsevier Inc. on behalf of The American Association for Thoracic Surgery

https://doi.org/10.1016/j.jtcvs.2019.07.082
}

In this issue of the Journal, Nobel and colleagues ${ }^{1}$ report the results of their study on the development of esophageal cancer across the spectrum of age in the National Cancer Database. They voice some concern that younger patients with symptoms or signs of disease may not be getting the appropriate attention and diagnostic workup simply because of their age, supporting this hypothesis with data suggesting that the younger patients in their study cohort have more advanced disease diagnosed (with a significant percentage of metastatic disease at the time of diagnosis). Unfortunately, one seldom gets a chance to make up for a delayed diagnosis for any cancer, especially esophageal cancer. Nobel and colleagues ${ }^{1}$ conclude that a higher index of suspicion for esophageal cancer should be applied when caring for younger patients with obesity and reflux.

As with all big national database studies, lack of granularity of data and quality control across the spectrum of contributing sites is an incontrovertible (and inescapable) limitation. This is always thought to be effectively balanced by access to a massive number of patients for recruitment; however, more data are not as valuable as good data. Moreover, both author and reader alike need to be acutely aware of limitations of the questions being asked and those answered. To their credit, this authorship team seems to have asked a very simple question of the data and were greeted with a seemingly straightforward answer. That this is more of a descriptive study certainly leverages the strength of the National Cancer Database, and very little can be questioned in regard to the findings.

So, if we believe the question asked and the answer returned, all that remains is the interpretation and inference. Nobel and colleagues ${ }^{1}$ suggest that esophageal cancer is underdiagnosed in younger patients and argue for heightened awareness, as stated previously. What we all need to know is how big a deal is esophageal cancer in terms of prevalence in the population? Are there any other reasons that younger patients have more advanced disease? How young is young? And how hard should we look?

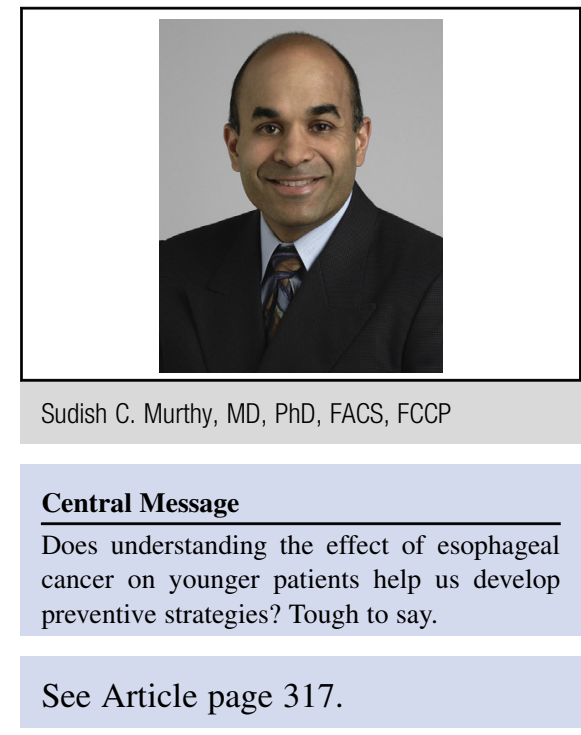

Esophageal cancer is still a fairly rare disease, despite its increasing prevalence. Conservatively, it is at least an order of magnitude less prevalent than breast, lung, prostate, or colon cancer; however, its lethality supersedes all. So yes, it is always a bad disease when encountered, seemingly even worse in younger patients, but how much should we change health care policy for a disease that may be affecting very few (in comparison), and what would we have to give up from a health care cost-shifting standpoint to be able to screen more aggressively for this disease in the young (perhaps with endoscopy)? It took almost 2 decades to get lung cancer screening going, and that at-risk population has been far better defined and is much larger. For lung cancer, prevalence in screened populations is at least $1 \%$ now. But could we really even consider screening for esophageal cancer? We are not exactly sure who comprise the high-risk group for esophageal cancer at this point, are we? Those with reflux of some unclear duration? Obese patients? Smokers?

How young is young? Because this is such a rare disease, Nobel and colleagues ${ }^{1}$ had to lump together everyone from age 18 to 57 to make up their "young" group. That is a huge number of patients in the denominator, and the prevalence of this disease in this group is probably extremely small. Unfortunately, we have no idea how many at-risk patients it took to get the approximately 2000 patients/year logged into the National Cancer Database. Just so that the reader is aware, this is a 39-year spread; the other study quartiles represent 8-year spreads (save for the last, the $>75$-year group). 
Finally, have Nobel and colleagues ${ }^{1}$ just identified a group of patients who get seemingly worse disease? We have seen this before. Breast and colorectal cancer arising in younger patients ultimately led to the discovery of germline mutations conferring extreme risk for these specific cancers. Perhaps we should think along the same lines here and enroll these patients into similar mutation fishing expeditions.
This is a very thought-provoking study, but we need to tread a bit lightly with these data for now. Else we run the risk of trying to find a cancer in a haystack... and that will not be easy (or cheap).

\section{Reference}

1. Nobel TB, Curry M, Gennarelli R, Jones DR, Molena D. Higher clinical suspicion is needed for prompt diagnosis of esophageal adenocarcinoma in young patients. J Thorac Cardiovasc Surg. 2020;159:317-26.e5. 